\title{
Porous polymeric membranes with thermal and solvent resistance
}

\author{
B. Pulido ${ }^{\mathrm{a}}$, C. Waldron ${ }^{\mathrm{a}}$, M. G. Zolotukhin ${ }^{\mathrm{b}}$ and S. P. Nunes ${ }^{\mathrm{a} \star}$
}

${ }^{a}$ King Abdullah University of Science and Technology (KAUST), Biological and Environmental Science and Engineering Division (BESE), 23955-6900 Thuwal, Saudi Arabia.

bUniversidad Nacional Autónoma de Mexico (UNAM), Instituto de Investigaciones en Materiales (IIM), 04510 Ciudad de México, México.

${ }^{\star}$ Corresponding author:

Prof. Suzana Nunes, suzana.nunes@ kaust.edu.sa 


\begin{abstract}
Polymeric membranes are highly advantageous over their ceramic counterparts in terms of the simplicity of the manufacturing process, cost and scalability. Their main disadvantages are low stability at temperatures above $200{ }^{\circ} \mathrm{C}$, and in organic solvents. We report for the first time porous polymeric membranes manufactured from poly(oxindolebiphenylylene) (POXI), a polymer with thermal stability as high as $500{ }^{\circ} \mathrm{C}$ in oxidative conditions. The membranes were prepared by solution casting and phase inversion by immersion in water. The asymmetric porous morphology was characterized by scanning electronic microscopy. The pristine membranes are stable in alcohols, acetone, acetonitrile and hexane, as well as in aqueous solutions with $\mathrm{pH}$ between 0 and 14. The membrane stability was extended for application in other organic solvents by crosslinking, using various dibromides, and the efficiency of the different crosslinkers was evaluated by thermogravimetric analysis (TGA) and X-ray photoelectron spectroscopy (XPS). POXI crosslinked membranes are stable up to $329{ }^{\circ} \mathrm{C}$ in oxidative conditions and showed organic solvent resistance in polar aprotic solvents with $99 \%$ rejection of Red Direct 80 in DMF at $70{ }^{\circ} \mathrm{C}$. With this development, the application of polymeric membranes could be extended to high temperature and harsh environments, fields currently dominated by ceramic membranes.
\end{abstract}

Keywords: Poly(oxindolebiphenylylene), organic solvent nanofiltration; solvent resistant nanofiltration; harsh conditions filtration; crosslinking; high performance polymers 


\section{Introduction}

Membranes are essential components of water treatment systems used for desalination and different medical and pharmaceutical separation and purification processes $[1,2]$. Polysulfone, cellulose acetate, polyacrylonitrile and poly(vinylidene fluoride) are the main materials for membrane fabrication, which can be easily achieved in continuous machines and manufactured into modules. Polymeric membranes are up to five times cheaper than ceramics, the preparation is simpler, easy to scale-up, the packing density in modules is higher and sealing is easily done. Compared to ceramic analogs, polymeric membranes are also less brittle. However, the use of conventional polymeric membranes for challenging processes is limited to relatively mild operational conditions, within a range of solvents, temperatures and $\mathrm{pH}$. Usually, when harsh conditions arise or operation at temperatures above $100{ }^{\circ} \mathrm{C}$ is needed, ceramic membranes prevail [3]. This is the case of the following processes: (i) agro food industry for high temperature separation processes using organic solvents; (ii) production of chemically modified sugars in Nmethylpyrrolidone; (iii) treatment of sugar juices, for the purification of clarified juices, with sugar concentration ranging from 7 to $25^{\circ}$ Brix and a feed solution temperature of $90-100^{\circ} \mathrm{C}$; (iv) treatment of different wastewater in the dye industry, in alkaline solutions from bottle washing machines, or in bath solutions from the metal working industry as well as for the treatment of nuclear wastewater [4-7].

Polymeric membranes with better chemical and thermal stability would extend the applications to conditions currently only covered by ceramics [8], keeping the advantages in their manufacture and module characteristics. High performance polymers are available with stability at temperatures even higher than $400{ }^{\circ} \mathrm{C}[9,10]$.

There is a limited selection of polymeric membranes available for harsh conditions. Good examples are SelRO ${ }^{\mathrm{TM}}$ membranes. Goatley et al. [11] reported the use of different grades of commercial SelRO ${ }^{\mathrm{TM}}$ membranes, which were stable over a wide $\mathrm{pH}$ range $(\mathrm{pH}$ 0 to 14), with an operation temperature of $80^{\circ} \mathrm{C}$, and in different solvents. Ba et al. [12] demonstrated that P84 copolymide membranes coated by polyethylenimine could be used in nanofiltration for salt separation, withstanding mildly acidic and basic conditions $(2 \leq$ $\mathrm{pH} \leq 10)$, and organic solvents. Thin composite membranes, made from poly(phthalazinone ether sulfone ketones)s and polysulfone [13] were used for salt and dye separation. $\mathrm{pH}$-stable membranes could be applied in many industrial process streams, such as the treatment of acidic and basic streams in pulp and paper manufacture and in the pharmaceutical and paint industries [14]. The examples above are however a relatively small number, compared to the large number of membranes developed and tested for aqueous media at room temperature.

A notable growing field is that of solvent resistant nanofiltration (SRNF) membranes, also known as organic solvent nanofiltration (OSN) membranes, with the perspective of applications in the pharmaceutical and chemical industries. Membrane technology could allow more efficient separation and purification processes in organic solvents, compared to traditional processes (distillation, selective crystallization, etc.). For example, one of 
the most promising applications for OSN is the recovery of transition metal catalysts from homogeneous catalytic reactions [15-17]. Pioneering work on the development of solvent resistant membranes was conducted by Linder and coworkers [18]. Excellent reviews on this topic have been published by Livingston's [19] and Vankelecom's [20] groups. The main requirement for successful implementation of SRNF or OSN is the development, understanding and implementation of membranes able to withstand organic solvent conditions [21]. This can be achieved by tuning the polymer solubility by polymer modification [22] or by crosslinking [23, 24]. Crosslinked polyimide [25], polyetherketone [22] and polybenzimidazole [23, 26] are some of the polymers used for solvent resistant membranes, and the use of hollow fibers was reported by Chung and coworkers [25]. Mix-matrix membranes for OSN have also been reported [27].

Polyoxadiazole membranes have been applied in harsh conditions [28, 29]. Fluorinated polyoxadiazole is a high performance polymer, previously used for fuel cell technology $[30,31]$, which also requires high stability in acids, and in oxidative media. The polymer has a glass transition temperature $\left(T_{g}\right)$ close to $300^{\circ} \mathrm{C}$, with degradation temperature of $475{ }^{\circ} \mathrm{C}$. We are now exploring other polymers for membrane preparation with stability at extreme conditions. During the last decade, a new family of high performance polymers [32-34], based on the superacid condensation of isatin and different arylene monomers have been prepared and studied. Poly(oxindolebiphenylylene) dense films were evaluated for gas separation [35] and fuel cells [36]. This material shows good solvent stability, mechanical strength and high glass transition temperature, desirable properties to prepare porous membranes for challenging applications, where chemical and thermal stability are needed. In this work, our aim is to explore the preparation and performance of porous asymmetric poly(oxindolebiphenylylene)s membranes crosslinked with various dibromides, in order to extend their application in organic solvents and at high temperatures.

\section{Experimental}

\subsection{Materials}

All chemical reagents are commercially available. Isatin, biphenyl, trifluoroacetic acid (TFA), trifluorosulfonic acid (TFSA), methylene chloride, 1-bromooctane (BO), 1,8dibromooctane (DBO), 1,4-dribromobutane (DBB), 1,4-diiodobutane (DIB), 1,4dibromo-2,3-butadione (DBD), $\alpha, \alpha^{\prime}$-dibromo-p-xylene (DBX), N-methyl pyrrolidone (NMP), dimethylsulfoxide (DMSO), dimethylformamide (DMF), dimethylacetamide (DMAc), acetonitrile $(\mathrm{MeCN})$, potassium carbonate $\left(\mathrm{K}_{2} \mathrm{CO}_{3}\right)$, poly (ethylene glycol) (PEG), different molecular weights, were obtained from Sigma-Aldrich. 1,5-dibromo1,1,2,2,5,5-hexafluropentane (DBHF) was obtained from VWR. Isatin was purified by recrystallization from ethanol with charcoal. TFA and TFSA were purified by distillation. The rest of the reagents were used as received.

2.2 Synthesis of poly(oxindolebiphenylylene)s (POXI) 
Poly(oxindolebiphenylylene) was prepared by superacid polycondensation reaction, as illustrated in Scheme 1, according to a synthesis route reported elsewhere [33]. In a typical POXI synthesis procedure, $4.65 \mathrm{~mL}$ of trifluoroacetic acid (TFA), and $8 \mathrm{~mL}$ of trifluorosulfonic acid (TFSA) are poured into a $20 \mathrm{~mL}$ one-necked round flask, followed by the addition of biphenyl ( $1.542 \mathrm{~g}, 0.01 \mathrm{~mol})$. The clear mixture is mechanically stirred and cooled in an ice/water bath. After biphenyl is completely solubilized, isatin (1.4715 $\mathrm{g}, 0.01 \mathrm{~mol}$ ) is added. The reaction is under nitrogen flux and the ice bath is kept for 10 minutes. After 3.5 hours a high viscosity solution is obtained. A red colored reaction mixture is observed, which is then quenched, by pouring it into methanol. The white fibrous product is filtered, copiously washed with methanol and dried in vacuum oven overnight.
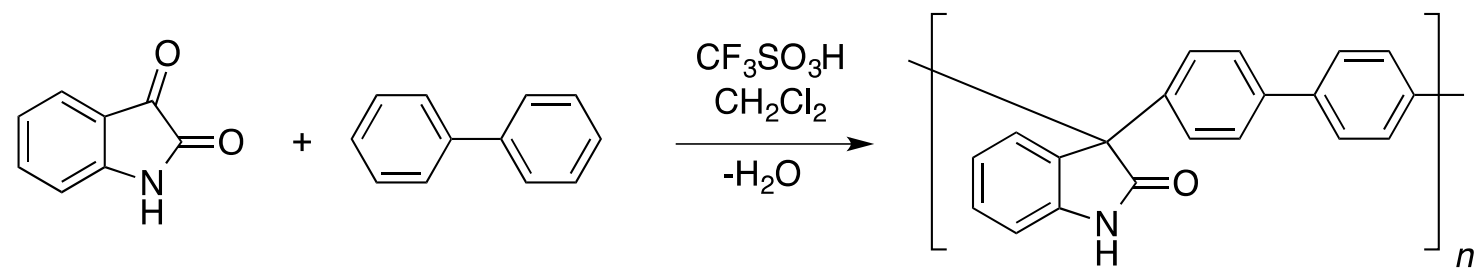

Scheme 1. Synthesis of poly(oxindolebiphenylylene)s (POXI) via superacid polycondensation.

\subsection{Preparation of POXI membranes by phase inversion}

POXI asymmetric porous membranes were prepared by non-solvent induced phase separation (NIPS) [37, 38]. POXI is soluble in organic, aprotic, and polar solvents, such as NMP, DMSO, DMF and DMAc. Polymer solutions in NMP (10 wt $\%, 12 \mathrm{wt} \%, 14 \mathrm{wt} \%$, $15 \mathrm{wt} \%)$, DMSO (10 wt $\%, 12 \mathrm{wt} \%)$, DMAc (12wt \%), and DMF (12wt \%) were prepared. The polymer solutions were stirred during $12 \mathrm{~h}$ at ambient temperature, followed by a $12 \mathrm{~h}$ resting time to eliminate air bubbles. Membranes were prepared by casting the polymer solution onto a clean glass surface with a metal rod with a $150 \mu \mathrm{m}$ gap. No evaporation was promoted before immersion into a Milli-Q water coagulation bath at ambient temperature.

\subsection{Membrane crosslinking}

Membranes prepared from $14 \%$ wt solutions in NMP were modified by immersion in a refluxing stirred solution of the crosslinker $(0.002 \mathrm{~mol})$ in acetonitrile $(10 \mathrm{~g})$ in the presence of $\mathrm{K}_{2} \mathrm{CO}_{3}(0.5 \mathrm{~g})$ for $24 \mathrm{~h}$ (see Scheme 2). The used crosslinkers are depicted in Scheme 3. After modification the membrane was thoroughly washed with clean acetonitrile. 

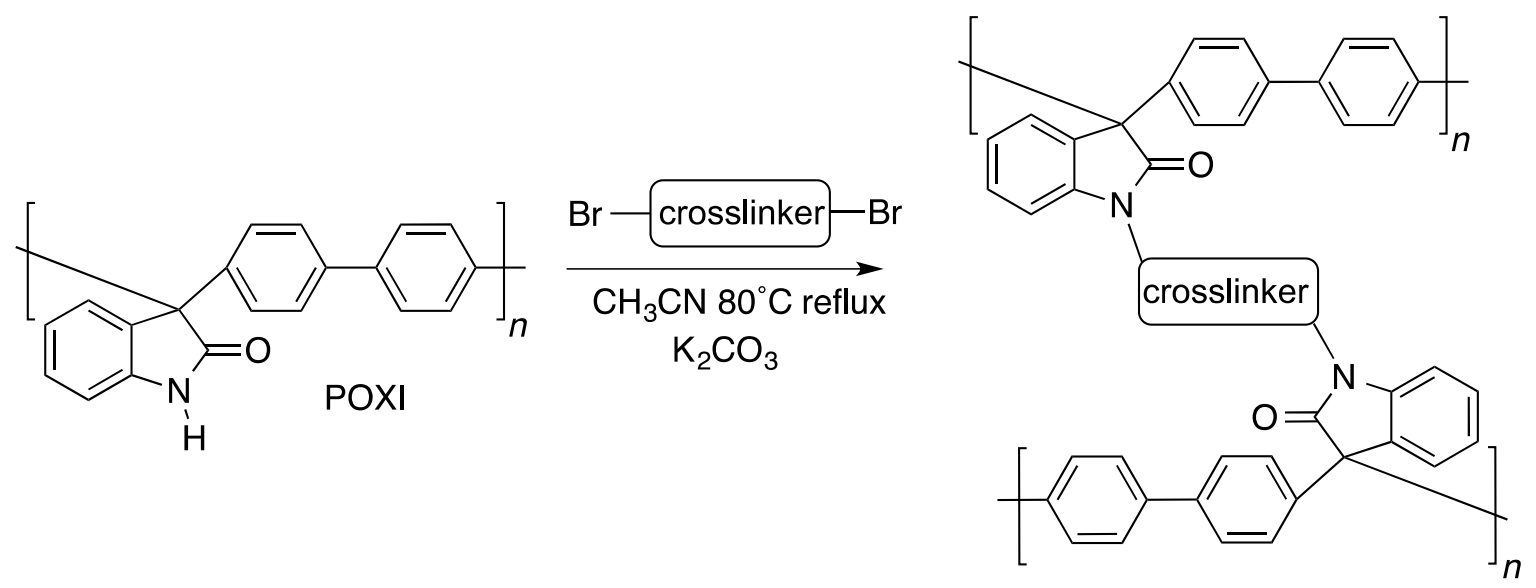

Scheme 2. Chemical modification reaction for POXI membranes.<smiles>FC(F)(Br)CC(F)(F)CC(F)(F)Br</smiles><smiles>O=C(O)CCCCCCCBr</smiles><smiles>[R10][R]</smiles><smiles>O=C(CBr)C(=O)CBr</smiles>

$\mathrm{Br}$<smiles>[3H]CCCCCCC</smiles>

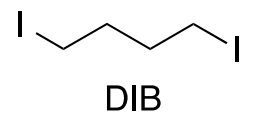<smiles>BrCCCCBr</smiles>

Scheme 3. Chemical structure of crosslinkers used for membrane modification.

\subsection{Characterization}

Spectroscopy

The synthetized polymer was characterized by proton and carbon nuclear magnetic resonance $\left({ }^{1} \mathrm{H}-\mathrm{NMR}\right.$ and $\left.{ }^{13} \mathrm{C}-\mathrm{NMR}\right)$ spectroscopy. The NMR spectra was recorded in a Bruker Avance-III $400 \mathrm{MHz}$ and $600 \mathrm{MHz}$ NMR spectrometer equipped with a Z-axis gradient $\mathrm{BBO}$ probe and a B-ACS 60 automatic sample changer. The sample was solubilized in DMSO- $d_{6}$.

The Fourier Transformed Infrared (FT-IR) spectra of the polymers and crosslinked membranes were obtained on a Thermo Scientific Nicolet iS10 FTIR Spectrometer equipped with a universal attenuated total reflectance (ATR) sampling accessory. Data were collected over 64 scans with spectral resolution of $4 \mathrm{~cm}^{-1}$ from 500 to $4000 \mathrm{~cm}^{-1}$. The X-ray photoelectron spectroscopy (XPS) experiments were performed on a Kratos Axis Ultra DLD instrument equipped with a monochromatic Al $\mathrm{K} \alpha$ x-ray source ( $\mathrm{h} v=$ $1486.6 \mathrm{eV}$ ) operated at a power of $150 \mathrm{~W}$ and under UHV conditions in the range of 
$10^{-9}$ mbar. All spectra were recorded in hybrid mode using electrostatic and magnetic lenses and an aperture slot of $300 \mu \mathrm{m} \times 700 \mu \mathrm{m}$. The survey and high-resolution spectra were acquired at fixed analyzer pass energies of $160 \mathrm{eV}$ and $20 \mathrm{eV}$, respectively. The samples were mounted in floating mode in order to avoid differential charging. Therefore, XPS spectra were acquired using charge neutralization. We have ensured that the chemical structure of the polymer remains unchanged under prolonged X-ray and charge neutralizer bombardment. The effect of the X-ray and charge neutralizer on the polymer structure was investigated by acquiring three $\mathrm{C} 1 \mathrm{~s}$ spectra at the beginning of the experiment that were compared to three $\mathrm{C} 1 \mathrm{~s}$ spectra acquired at the end of the experiment. All $\mathrm{C} 1 \mathrm{~s}$ spectra were identical confirming the absence of damage.

Thermal and Mechanical Analysis

The thermal stability was evaluated by thermo gravimetric analysis (TGA) in a TA Instruments TGA-Q50 equipment from $25-800^{\circ} \mathrm{C}$ with a heat ramp of $10^{\circ} \mathrm{C} / \mathrm{min}$. The study was carried out in inert $\left(\mathrm{N}_{2}\right)$ and oxidative (Air) atmosphere.

The strain-stress curves for the membranes were obtained by dynamical mechanical analysis (DMA) using TA Instruments DMA-Q800 equipped with film tension clamp (torque limit of $3.4 \mathrm{~kg} \mathrm{~cm}$ ). Experiments were carried out at $25^{\circ} \mathrm{C}$ with controlled force method with a force ramp of $0.05 \mathrm{~N} / \mathrm{min}$ and a preload force of $0.001 \mathrm{~N}$. Five rectangular pieces were cut with $5 \mathrm{~mm}$ width and $15 \mathrm{~mm}$ length. The membrane thickness was measured with a Mitutoyo-Absolute micrometer and ProMax-Fowler caliper.

\section{Contact Angle}

The effect of crosslinking on the hydrophobicity of the membranes was analyzed by static contact angle water-membrane measurements in a KRUSS Easy Drop Goniometer with $0.16 \mathrm{~mL}$ volume drops. Samples were freeze-dried followed by vacuum oven overnight before the measurement. Reported contact angle values were averaged from five measurements.

\section{Scanning Electron Microscopy (FESEM)}

The morphology of the membranes was characterized by field emission scanning electron microscopy (FESEM) on a Nova Nano FEI microscope. All samples were freeze-dried, and for cross-sections membranes were fractured in liquid nitrogen, followed by sputtering under vacuum with $3 \mathrm{~nm}$ of Pt in a K575X Emitech equipment.

Organic Solvent Resistance

The organic solvent resistance was evaluated by immersing $2 \mathrm{mg}$ pieces of the crosslinked POXI membranes into $1.5 \mathrm{~mL}$ of selected solvents (DMF, DMAc, NMP and DMSO) during 40 days. The membrane stability was monitored by measuring the UV absorption of the solvent in contact with the membrane, using a Thermo Scientific Nanodrop 2000c UV-VIS Spectrometer, taking into account that any polymer fraction dissolved from the membrane would cause an increase of absorption, analogously to the procedure described before [29]. The integrity of the membrane or its resistance in organic solvent was quantified by Equation 1: 
Organic Solvent Resistance $(\%)=\left(1-\frac{A_{1}}{A_{0}}\right) 100$

where $A_{1}$ and $A_{0}$ are the absorptions of the solvent in contact with a defined weight of membrane after and before 40 days of exposure, respectively.

Filtration Experiments

The setup used for dead end filtration experiments consisted of dry $\mathrm{N}_{2}$ gas cylinder with gas pressure regulator. Water filtration experiments were performed on a plastic Amicon $^{\mathrm{TM}}$ cell with an effective area of $4.1 \mathrm{~cm}^{2}$ and a total volume capacity of $10 \mathrm{~mL}$, connected to a 4L water container. The water filtration experiments were performed at 3.5 bar. The pure water flux (PWF) was calculated by direct measurement of the permeate flow $\left(\mathrm{L} \mathrm{m}^{-2} \mathrm{~h}^{-1}\right)$ at different transmembrane pressures from 0.5 to 4 bar in 0.5 bar intervals.

For filtration experiments in organic solvents a stainless-steel cell was used with an effective area of $1.1 \mathrm{~cm}^{2}$ and total capacity of $300 \mathrm{~mL}$, with magnetic stirring to reduce concentration polarization. The permeance is defined as the volume of solvent per unit of membrane area per unit of time at a given transmembrane pressure according to Equation 2:

Permeance $=\frac{V}{A t \Delta P}\left(\mathrm{Lm}^{-2} \mathrm{~h}^{-1} \mathrm{bar}^{-1}\right)$

where $V$ is collected permeate volume, $A$ is the membrane area, $t$ is the time and $\Delta P$ the applied transmembrane pressure.

The rejection experiments in water were performed using $0.1 \%$ wt solutions of different PEG molecular weights. Two different PEG mixtures were used as feed: one containing $1,6,10,20 \mathrm{~kg} / \mathrm{mol}$ and another with 3, 6, 10, 20,35, $100 \mathrm{~kg} / \mathrm{mol}$ PEG's. The molecular weight cut off (MWCO) is defined as the lowest molecular weight solute in which $90 \%$ of the solute is retained by the membrane. For membranes with low MWCO, dyes were additionally used (Direct red 80, $1373 \mathrm{~g} / \mathrm{mol}$ and methylene blue $320 \mathrm{~g} / \mathrm{mol}$ ). The MWCO for the studied membranes was determined by gel permeation chromatography (GPC) in an Agilent Technology 1200 Series Chromatograph equipped with PL-Aquagel $\mathrm{OH}-40$ and $\mathrm{OH}-60$ with refractive index detector. Solute rejections were calculated by analyzing concentrations of feed $\left(C_{f}\right)$ and permeate $\left(C_{p}\right)$, according to Equation 3:

Solute Rejection $(\%)=100\left(C_{f}-C_{P}\right) / C_{f}$

\section{Results and discussion}

In the present study the polymer synthesis, the membrane preparation and modification are presented. The novel material poly(oxindolebiphenylylene), POXI was prepared from isatin and biphenyl monomers by superacid polycondensation (section 3.1), the obtained polymer was manufactured into phase inversion membranes from different organic 
solvent solutions (NMP, DMF, DMAc, DMSO) and the filtration performance was evaluated (section 3.2). The best performing membranes were selected and submitted to further modification, using different crosslinkers (section 3.3). Finally, (section 3.4) the crosslinked membranes were tested for organic solvent resistance filtration.

\subsection{Polymer synthesis}

POXI was obtained by superacid-catalyzed reaction polymerization, following Scheme 1. The one-pot, metal-free, room temperature method allows the easy preparation of polymers with good yield and high molecular weight in a few hours using commercially available materials. This methodology can be used for the synthesis of a broad family of polymers with different carbonyl and aromatic monomers [39]. A polymer with high decomposition temperature, high chemical resistance and good mechanical properties was obtained. The yield was $99 \%$. The resulting polymer had an inherent viscosity $\left(\eta_{\text {ihn }}\right)$ of $0.77 \mathrm{dL} / \mathrm{g}(\mathrm{NMP})$, measured at $25^{\circ} \mathrm{C}$ with a Lauda-Ubbelohde viscometer.

The product was characterized by FTIR and ${ }^{1} \mathrm{H}-\mathrm{NMR}$, as shown in Figure 1 . In the spectral region around $3000 \mathrm{~cm}^{-1}$ the $\mathrm{N}-\mathrm{H}$ and $\mathrm{C}-\mathrm{H}$ aromatic stretch vibrations can be observed. The strong peak at $\sim 1700 \mathrm{~cm}^{-1}$ corresponds to the carbonyl group from the oxindole ring. Absorption peaks from $1000 \mathrm{~cm}^{-1}$ to $1250 \mathrm{~cm}^{-1}$ can be attributed to $\mathrm{C}-\mathrm{N}$ vibrations: while the peaks from $1500 \mathrm{~cm}^{-1}$ to $1600 \mathrm{~cm}^{-1}$ are due to the $\mathrm{C}-\mathrm{C}$ aromatic ring stretching. The ${ }^{1} \mathrm{H}-\mathrm{NMR}$ spectrum confirms the expected chemical structure. The polymerization reaction follows the electrophilic aromatic substitution mechanism. Each phenyl ring from the biphenyl monomer will act as a para-/ortho- directing group, however, para-positions will be preferred due to steric hindrance on the ortho-positions. The polymer repeating unit possesses seven distinct hydrogen nuclei; six aromatic protons $(\delta: 6.99,7.26$ and $7.59 \mathrm{ppm}$ ), and an $\mathrm{N}-\mathrm{H}$ (proton 7) signal at a lower field with $\delta$ $=10.84 \mathrm{ppm}$. The coupling constant for protons 1 (doublet, $\mathrm{J}=7.65 \mathrm{~Hz}$ ) and 2 (doublet, $\mathrm{J}$ $=7.82 \mathrm{~Hz}$ ) correspond to a para- position substitution on the biphenyl. The clear spectrum is evidence of the high selectivity of the polymerization reaction and the welldefined chemical structure. Subsequent thermal analysis revealed a high decomposition temperature, and no $T_{\mathrm{g}}$ could be detected below $400^{\circ} \mathrm{C}$, which is advantageous compared with other polymers used in the field (Matrimid $T_{\mathrm{g}}=313{ }^{\circ} \mathrm{C}$ and polyphenylsulfone $T_{\mathrm{g}}=$ $220^{\circ} \mathrm{C}$ ). It preserves its mechanical properties in a large range of temperatures [33]. 


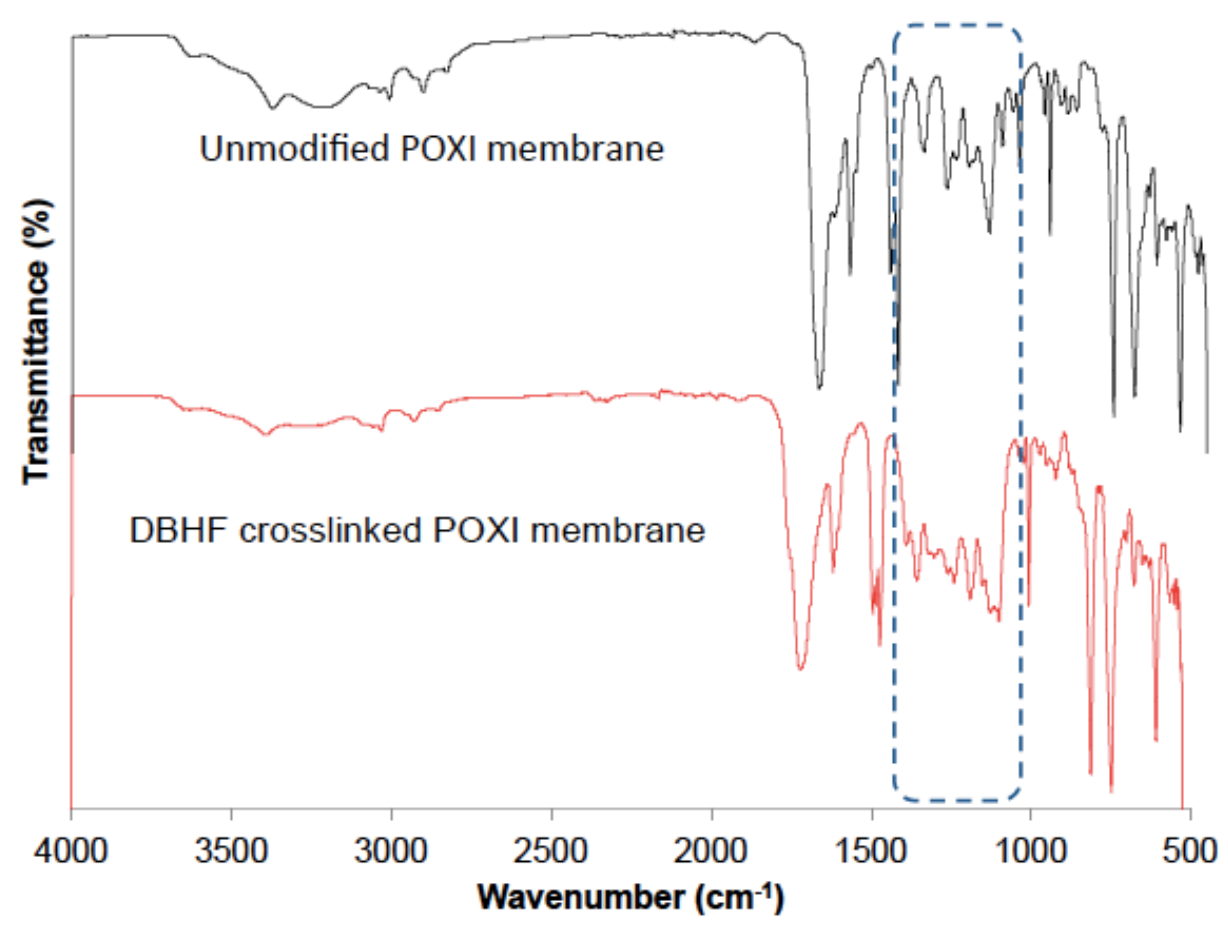

(a)

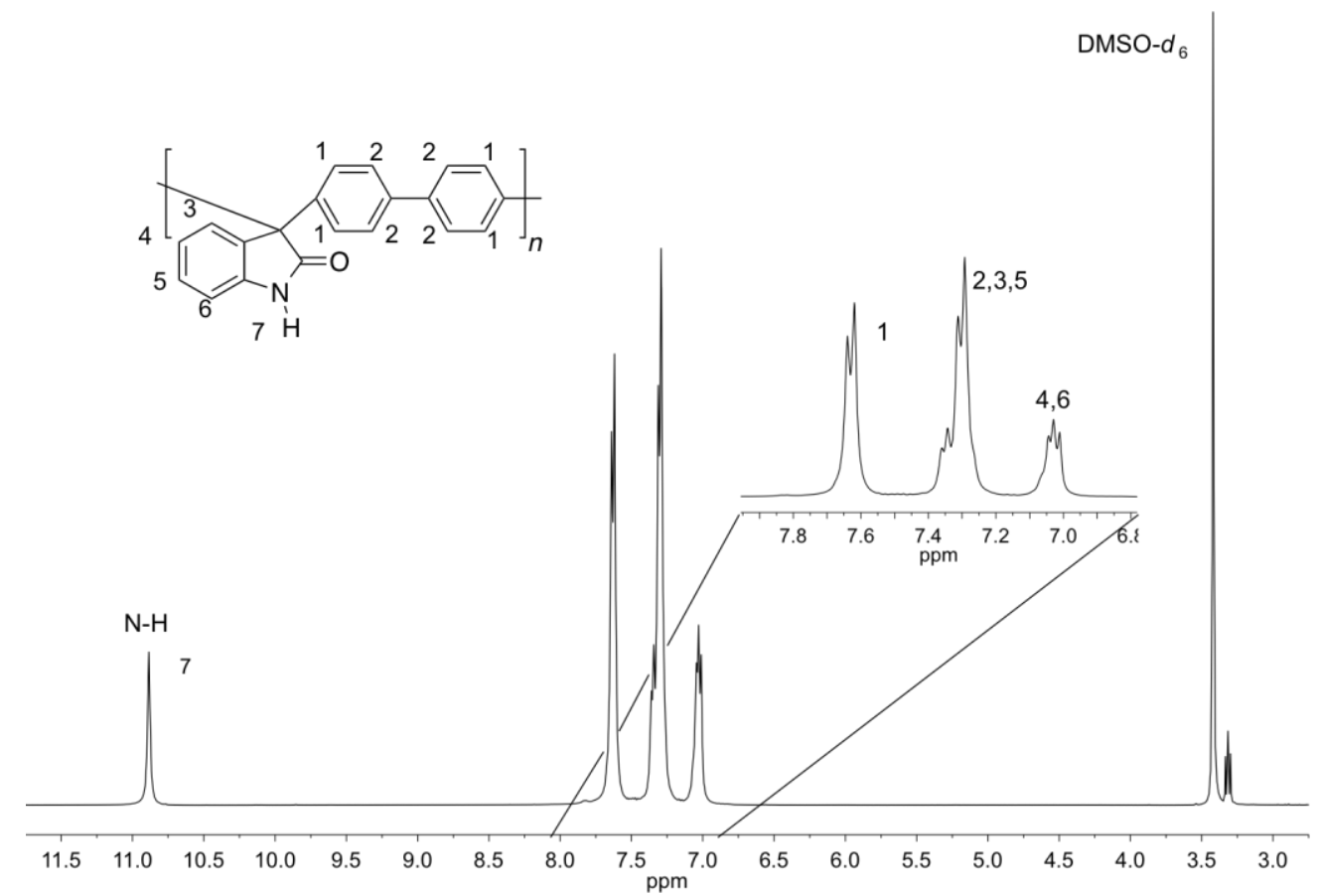

(b)

Figure 1. (a) ATR-FTIR of pristine POXI and POXI membrane crosslinked with DBHF; (b) ${ }^{1} \mathrm{H}-\mathrm{NMR}$ spectra of the synthesized POXI (solution in DMSO- $d_{6}$ ). 


\subsection{Non-crosslinked POXI Membrane Preparation and Characterization}

This is the first time that POXI was used to prepare porous membranes. When considering post-synthesis crosslinking or functionalization, POXI is an interesting polymer, due to its accessible functionalization via the $\mathrm{N}-\mathrm{H}$ group in the oxindole fragment. Self-standing (no need for a support) membranes can be prepared starting from $8 \mathrm{wt} \%$ solutions in NMP. Despite its rigid aromatic backbone, POXI is soluble in polar aprotic solvents, due to strong hydrogen bond and dipole interactions with the amide group in the oxindole ring.

The flexibility of POXI makes it possible to prepare membranes that are easy to handle and be used without the need for a support. In contrast, the high performance membranes used in organic solvent nanofiltration based on polybenzimidazole are frequently brittle and need to be cast onto polypropylene (PP) or polyester (PS) support to achieve acceptable mechanical stability.

Table 1 shows the values of inherent viscosity measured for $0.2 \mathrm{~g} / \mathrm{dL}$ POXI solutions in DMSO, DMAc, DMF, NMP, measured at $25^{\circ} \mathrm{C}$ with a Lauda-Ubbelohde viscometer.

They give a rough indication of the solvent quality for POXI, NMP being the best solvent, followed by DMSO, DMAc and DMF. When a good solvent is used, polymer coils unroll, increasing the viscosity of the solution.

Table 1. Dynamic and inherent viscosity measurements for polymer solutions in selected polar aprotic solvents.

\begin{tabular}{|c|c|c|}
\hline Solvent & Dynamic viscosity $(\mathrm{Pa}$ s) & Inherent viscosity $(\mathrm{dL} / \mathrm{g})$ \\
\hline DMSO & 1.99 & 0.67 \\
\hline NMP & 1.65 & 0.75 \\
\hline DMAc & 0.95 & 0.49 \\
\hline DMF & 0.92 & 0.41 \\
\hline
\end{tabular}

The effect of solvent and concentration on the membrane morphology and performance was then investigated. Membranes were prepared from $12 \mathrm{wt} \%$ POXI solutions in different solvents (DMSO, DMAc, NMP and DMF) and different concentrations in NMP, following the general methodology described in the experimental section. Figure 2 shows the membrane cross-section morphology imaged by FESEM. Macro voids are observed in membranes obtained from $10 \mathrm{wt} \%$ to $14 \mathrm{wt} \%$ POXI solutions in NMP. When $15 \mathrm{wt} \%$ solution was used a fully sponge-like structure was obtained. As viscosity of the solution increases, non-solvent exchange is slower preventing the macrovoid formation, as can be seen on Figure 2. This is also observed when a high viscosity solvent like DMSO is used in comparison with other solvents while keeping the same polymer concentration (12 wt $\%)$. 

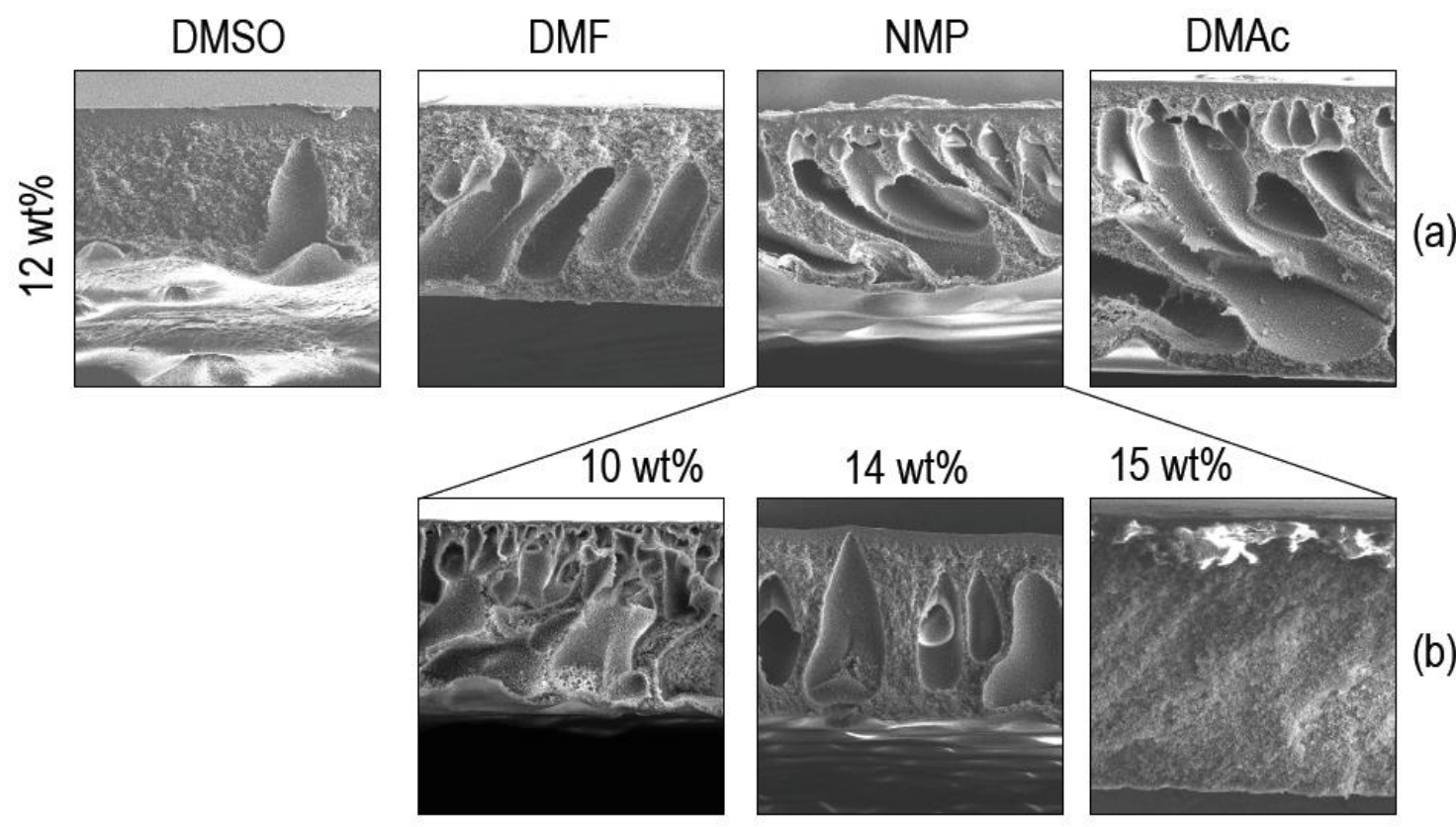

(a)

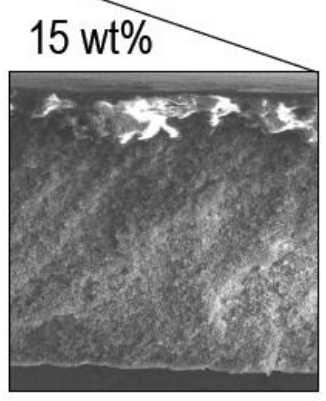

$50 \mu \mathrm{m}$

Figure 2. Cross-section images of membranes cast from (a) $12 \mathrm{wt} \%$ POXI solutions in DMSO, DMF, NMP, DMAc and (b) different concentrations of POXI solutions in NMP.

Permeation tests were performed with the prepared membranes. The water flux linearly increased with the applied pressure; this is an evidence of the membrane stability, i.e. no compaction or pore collapse. The selectivity of the membranes was then evaluated, by testing the rejection of low-molecular weight dye molecules, and a mixture of different molecular weights of PEG's, leading to the MWCO values shown in Figure 3. As expected, the permeance decreases as the casting polymer solution concentration increases. Solutions in DMSO were more viscous than in NMP. The maximum polymer concentration in DMSO chosen for membrane preparation was therefore $10 \mathrm{wt} \%$. Higher concentrations in DMSO resulted in uneven membranes. By increasing the polymer concentration in NMP from 12 to $14 \mathrm{wt} \%$ a substantial decrease of permeance was observed.

After filtration with PEG solutions, membranes were washed with MilliQ water for two hours to remove PEG, and pure water permeance was measured again. Water permeance values above $50 \mathrm{~L} \mathrm{~m}^{-2} \mathrm{~h}^{-1} \mathrm{bar}^{-1}$ were measured for all membranes prepared from $12 \mathrm{wt} \%$ polymer solutions, with high recovery of pure water permeance after filtration of PEG solutions. Membranes from $15 \mathrm{wt} \%$ solution in NMP have a fully sponge-like structure, as it can be seen in Figure 2. The permeance recovery after filtration with PEG was low in this case.

Figure 3 shows the MWCO values for all membranes, which are in the low range of ultrafiltration (UF). It can be seen that membranes cast from $14 \mathrm{wt} \%$ and $15 \mathrm{wt} \%$ polymer solution in NMP have similar MWCO. They rejected 100\% of Direct Red 80 
(1373 g/mol, $100 \mathrm{ppm}$ concentration). Since the permeance was better with $14 \mathrm{wt} \%$, these membranes were chosen for further modification and organic solvent applications.

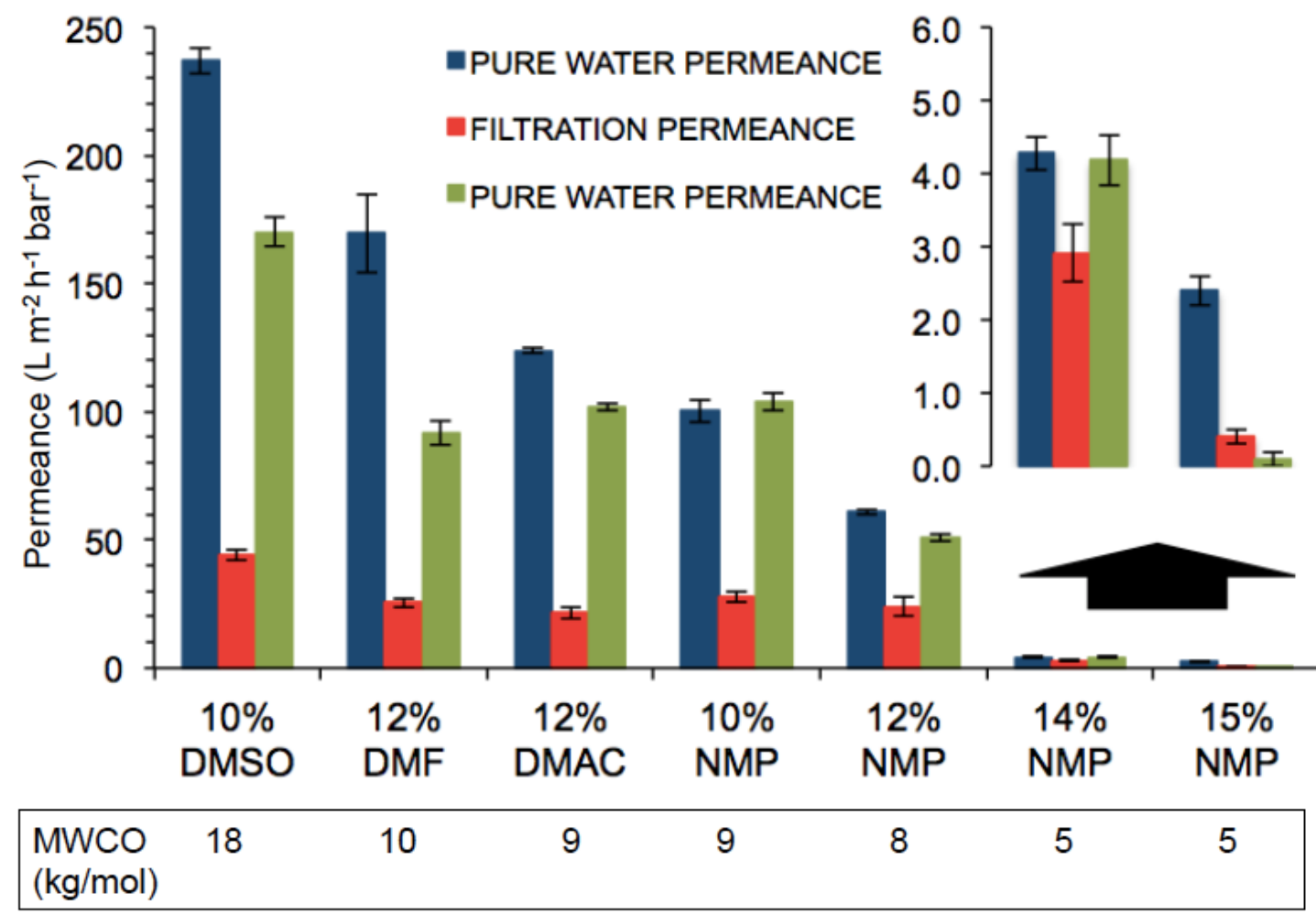

Figure 3. Water permeance experiments using pure water (blue), PEG solutions (red) and pure water again (green), after washing the membranes. 


\subsection{Crosslinking of POXI membranes}

The use of POXI has resulted in membranes with exceptional thermal properties. Figure 4 shows that the thermal degradation of POXI membranes starts above $500{ }^{\circ} \mathrm{C}$. This means an exceptional enlargement of the window of operation temperature for polymeric membranes, compared to the characteristics of currently commercial membranes.

As important as thermal stability is the solvent resistance. To address this issue, we investigated the chemical crosslinking with dibromides, using the strategy depicted in Scheme 2. The membrane modification takes place via the oxindole ring by the nucleophilic attack of the nitrogen towards electrophiles, in this case the immediate carbon to the halide. Two of the selected dibromides (DBB and DBX) were used before to crosslink polybenzimidazole (PBI) membranes for organic solvent resistant processes $[24,40]$. Herein, we studied a broader family of modifiers with varying chemical structures and reactivities, listed in Scheme 3. We investigated the effect of carbon chain structure (aromatic DBX / aliphatic DBB), halide (iodide DIB / bromide DBB), length (butane DBB / octane DBO) and bi/mono functionality (DBO, BO).

Previous work has shown that the complete modification of the oxindole group can be achieved from a NMP polymer solution after 24 hours in the presence of $\mathrm{K}_{2} \mathrm{CO}_{3}$ at room temperature [33]. However, for the heterogeneous membrane modification, acetonitrile was used as non-solvent polar aprotic reaction medium, since the membranes are insoluble in it, but soluble in NMP. All modifiers were solubilized in acetonitrile with a high stoichiometric molar ratio (10:1) with respect to the monomeric unit.

TGA was used in order to quantify the weight loss associated to the crosslinker, and by inference, to determine the extent of crosslinking. TGA analysis (Figure 4, Table 2) was performed in both oxidative (air) and inert (nitrogen) atmospheres. The crosslinkers are placed in descending order from the higher (DBD) to the smaller (DBHF) weight loss percentage (WLP). These values were obtained by using the difference in WLP before and after the $1^{\text {st }}$ degradation step on the thermograms (determined by onset method). From the chart, it can be seen that all crosslinkers segments containing C-H, C-C, C-X bonds degrade in the temperature range from $246{ }^{\circ} \mathrm{C}$ to $294{ }^{\circ} \mathrm{C}$ in the oxidative atmosphere and from $255^{\circ} \mathrm{C}$ to $307^{\circ} \mathrm{C}$ in inert atmosphere. $\mathrm{DBD}$, which contains a $\mathrm{C}-\mathrm{O}$ bond, seems to have a lower thermal resistance with a degradation temperature at $223{ }^{\circ} \mathrm{C}$ (air) and $219{ }^{\circ} \mathrm{C}$ (nitrogen). The DBHF shows the most remarkable thermal resistance, with degradation temperatures as high as $329{ }^{\circ} \mathrm{C}$ (air) and $344{ }^{\circ} \mathrm{C}$ (nitrogen). This is a very positive aspect, which considerably enhances the temperature application window for the DBHF-POXI modified membrane is enhanced as a result. In general, the WLP in oxidative atmosphere is slightly higher, due to oxidation processes during the degradation (adding oxygen to the sample, and therefore mass). The $2^{\text {nd }}$ degradation step is related to the POXI backbone and the influence of crosslinker in this case is not relevant. The CXPOXI columns in Table 2 list the crosslinker molar ratios (modifier relative to polymer repeating unit (POXI)), calculated based on the TGA results. Since all modifiers have 
different molecular weights, the molar ratios are a clearer indication of the extent of crosslinking than weight percent. The values were estimated in air and inert atmosphere.

Additional experiments were then performed, adding DBX to the casting solution, before the membrane preparation. The membrane cast from the DBX enriched POXI solution in NMP (DBX enrich$)$ was modified with the same protocol reported in Scheme 2. By this strategy, a higher incorporation was obtained, $0.21 \mathrm{CX}$ :POXI mol ratio against 0.08 from the non enriched. All membranes were reacted for a period of two days. One day modification using DBHF and DBD was enough to achieve the substitution limit for DBHF (0.15 CX:POXI mol ratio), however for DBD the mol ratio went from 0.21 to 0.42 , when time was increased, indicating that one day is not sufficient for complete modification.

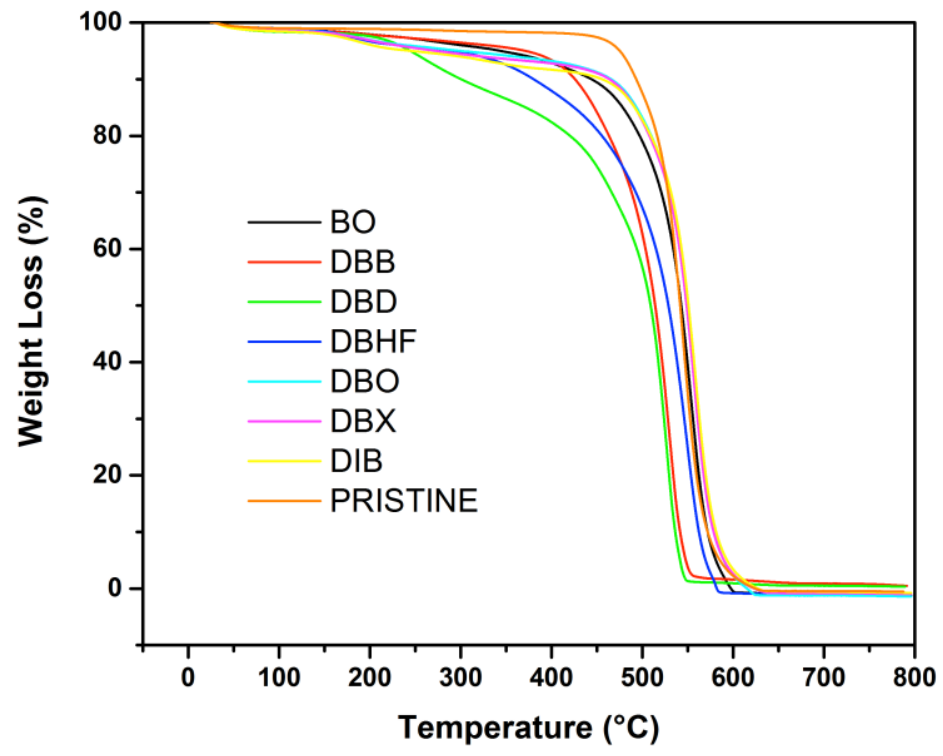

Figure 4. TGA curves of POXI pristine and modified membranes in oxidative atmosphere. 
Table 2. Thermal stability data for POXI non-crosslinked and crosslinked membranes in oxidative and inert atmospheres; molar ratios of crosslinker per POXI membrane polymer repeating unit are presented, calculated from thermogravimetrical analysis (TGA).

\begin{tabular}{|l|c|c|c|c|c|c|c|c|}
\hline \multirow{3}{*}{$\begin{array}{c}\text { Cross- } \\
\text { linker }\end{array}$} & \multicolumn{4}{|c|}{ Oxidative atmosphere } & \multicolumn{4}{c|}{ Inert atmosphere } \\
\cline { 2 - 9 } & $\begin{array}{c}\text { Weight } \\
\text { loss }\end{array}$ & $\begin{array}{c}1 \text { 1st } \\
\text { degradation }\end{array}$ & $\begin{array}{c}\text { 2nd } \\
\text { degradation }\end{array}$ & $\begin{array}{c}\text { CX:POXI } \\
(\%)\end{array}$ & $\begin{array}{c}\text { Weight } \\
\text { loss }\end{array}$ & $\begin{array}{c}\text { 1st } \\
\text { degradation }\end{array}$ & $\begin{array}{c}\text { 2nd } \\
\text { degradation }\end{array}$ & $\begin{array}{c}\text { CX:POXI } \\
(\text { mol }\end{array}$ \\
\hline DBD & 11.1 & 223 & 504 & 0.42 & 10.3 & 219 & 517 & 0.39 \\
\hline DBHF & 8.5 & 329 & 511 & 0.15 & 10.9 & 344 & 543 & 0.19 \\
\hline BO & 4.3 & 246 & 520 & 0.11 & 2.2 & 248 & 518 & 0.06 \\
\hline DIB & 3.4 & 294 & 527 & 0.18 & 2.6 & 307 & 537 & 0.14 \\
\hline DBX & 2.8 & 270 & 525 & 0.08 & 2.2 & 268 & 539 & 0.06 \\
\hline DBO & 2.8 & 265 & 527 & 0.07 & 2.7 & 257 & 532 & 0.07 \\
\hline DBB & 2.5 & 278 & 496 & 0.13 & 1.8 & 257 & 508 & 0.09 \\
\hline DBX enrich & 7.3 & 285 & 495 & 0.21 & 7.3 & 317 & 516 & 0.21 \\
\hline DBHF1day & 8.4 & 339 & 516 & 0.15 & 8.4 & 346 & 544 & 0.15 \\
\hline DBD 1day & 7.0 & 252 & 509 & 0.25 & 7.3 & 245 & 532 & 0.26 \\
\hline None & ---- & ---- & 522 & ---- & ---- & ---- & 543 & ---- \\
\hline
\end{tabular}

Complementing the TGA results, the membranes were analyzed using X-ray photoelectron spectroscopy (XPS), which can be used to accurately determine the surface $(\sim 0-10 \mathrm{~nm})$ elemental stoichiometries of the samples, validating the TGA data. The widescan XPS spectra, and sensitivity-factor corrected spectral area ratios with peak assignments for each membrane (pristine, plus DBHF, DIB, BO and DBD crosslinked) are given in Figure 5 and Table 3.

Initially the pristine, non-crosslinked membrane was examined. This analysis shows four major peaks in the wide-scan spectrum (Figure 5a) with binding energies of (BEs) 284, 531.40 , and $399.10 \mathrm{eV}$, which correspond to $\mathrm{C} 1 \mathrm{~s}, \mathrm{O} 1 \mathrm{~s}$, and $\mathrm{N} 1 \mathrm{~s}$, and are consistent with the chemical structure of the material. A discrepancy between the $\mathrm{O}$ and $\mathrm{N}$ ratios can be seen (which should be 1:1), however this is a common phenomenon and can be attributed to oxidation of the surface, or otherwise adventitious contamination with oxygen or water.

In the case of the DBHF crosslinked membrane (Figure $5 b$ ), in addition to the main $\mathrm{C}, \mathrm{O}$ and $\mathrm{N}$ peaks previously seen, the XPS spectrum shows a new peak at $687 \mathrm{eV}$, attributable to $\mathrm{F} 1 \mathrm{~s}$ and is proof that the crosslinker has been chemically incorporated into the structure. The XPS-derived elemental compositions are also in close agreement with the previous elemental analysis provided by TGA, and thus these results provide validation for both methods. Furthermore, this also demonstrates that the membrane modification is homogeneous, since TGA accounts for the membrane bulk properties, while XPS evaluates only the surface.

A crucial observation regarding the POXI membranes modified with DBHF, BO and DIB is that there is an absence (or near absence in the case of DIB, with an I at\% of 0.03) of bromine and iodine atoms, originally present in the crosslinker molecule, which is an 
evidence of (i) no halide-salt formation by nitrogen quaternization, in opposite to previous observations [24] for PBI modified with similar methodology; (ii) reaction of both terminal halide groups of the crosslinker and (iii) no residual unreacted crosslinker trapped in the polymer matrix. This is particularly notable in the case of DBHF, where the fluorine atoms of the crosslinker can be detected, but no bromine.

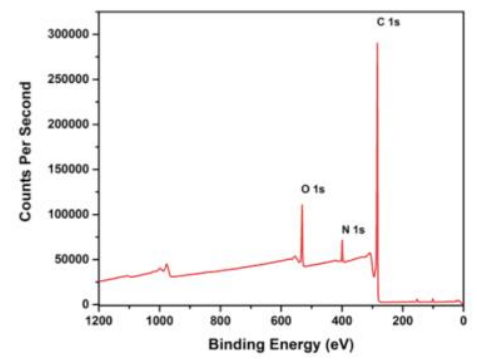

(a) Unmodified

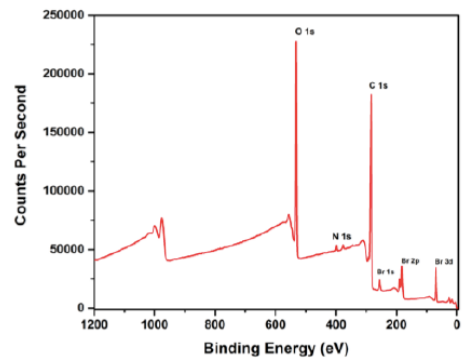

(c) DBD-modified

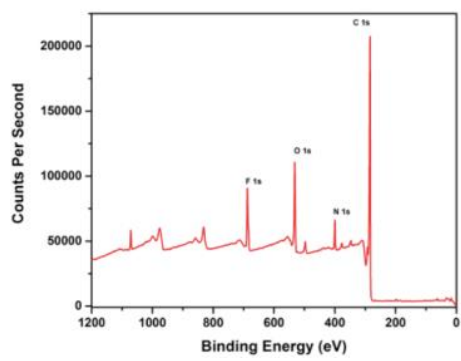

(b) DBHF-modified

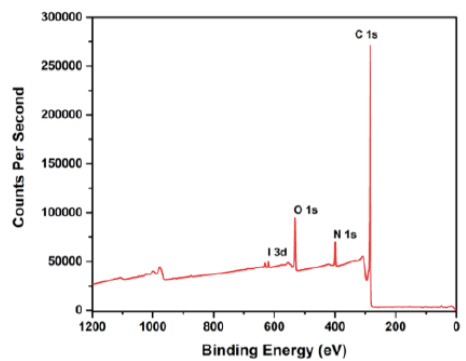

(d) DIB-modified

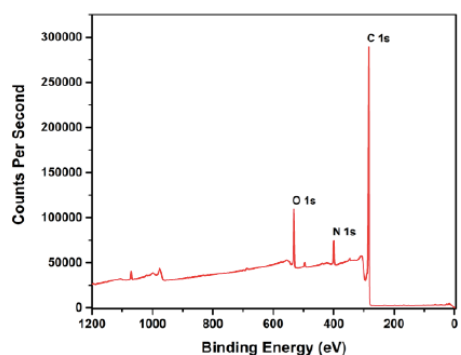

(e) BO-modified

Figure 5. XPS spectra for (a) unmodified and (b-e) modified POXI membranes, showingcharacteristic peaks for elemental composition. 
Table 3. XPS data with peak assignment, binding energy (eV) and atom \% for unmodified and modified POXI membranes.

\begin{tabular}{|c|c|c|c|}
\hline Membrane & Binding Energy (eV) & Assignment & Atom \% \\
\hline \multirow[t]{3}{*}{ Unmodified POXI } & 284 & C 1s & 88.7 \\
\hline & 399 & $\mathrm{~N} 1 \mathrm{~s}$ & 3.8 \\
\hline & 531 & $01 \mathrm{~s}$ & 7.5 \\
\hline \multirow[t]{4}{*}{ DBHF modified } & 284 & C 1s & 88.2 \\
\hline & 399 & $\mathrm{~N} 1 \mathrm{~s}$ & 4.0 \\
\hline & 531 & $01 \mathrm{~s}$ & 9.3 \\
\hline & 687 & F 1s & 4.6 \\
\hline \multirow[t]{4}{*}{ DBD modified } & 182 & $\mathrm{Br} 3 p$ & 3.5 \\
\hline & 284 & C 1s & 74.1 \\
\hline & 399 & $\mathrm{~N} 1 \mathrm{~s}$ & 0.7 \\
\hline & 531 & $01 \mathrm{~s}$ & 21.7 \\
\hline \multirow[t]{4}{*}{ DIB modified } & 284 & C 1s & 89.4 \\
\hline & 399 & $\mathrm{~N} 1 \mathrm{~s}$ & 4.1 \\
\hline & 531 & $01 \mathrm{~s}$ & 6.4 \\
\hline & 619 & $13 d$ & 0.07 \\
\hline \multirow[t]{3}{*}{ BO modified } & 284 & C 1s & 88.9 \\
\hline & 399 & $\mathrm{~N} 1 \mathrm{~s}$ & 4.0 \\
\hline & 531 & $01 \mathrm{~s}$ & 7.1 \\
\hline
\end{tabular}

Membrane modifiers:

DBHF: dibromohexafluoropentane; DBD: dibromobutadione; DIB: diiodobutane; BO: bromooctane.

Except for bromooctane (BO), all modifiers were bifunctional and should lead to a crosslinked membrane. However, BO incorporation into the membrane accounts for 0.11 BO:POXI mol ratio, which was enough to inhibit the solubility in NMP and other organic common solvents, probably by the removal of hydrogen bond opportunities, therefore reducing the interaction between solvent and polymer. All modified membranes were insoluble.

Although all modified membranes were insoluble in organic solvents, only the DBHFand DBD-modified ones have enough physical integrity to be used as filtration membranes, the rest of them swelling considerably or being easily broken. Considering the modifiers used in this study, DBHF seems to be the most compelling case as the crosslinker of choice, given the desired applications of the membranes. DBHF has high reactivity, and thermal resistance conferred from its fluorinated backbone; the C-F bonds are stronger $(116 \mathrm{kcal} / \mathrm{mol})$ than $\mathrm{C}-\mathrm{H}(104 \mathrm{kcal} / \mathrm{mol})$ bonds [41] of analogous aliphatic crosslinkers. Moreover, DBHF posses a higher reactivity towards nucleophilic substitution, due to the high electronegativity difference between carbon and fluorine, providing in this way a strong electron-withdrawing effect on terminal carbon atoms, in addition to the already present nucleophilic activation by the bromine.

FTIR spectra of all membranes showed little or no change for most membrane modification, due to the relatively small amount of substitution. Only in the case of DBHF (Figure 1) the emergence of new absorption peaks could be seen in the 1000-1360 $\mathrm{cm}^{-1}$ wavenumber range, which are characteristic of $-\mathrm{CF}_{2-}$ stretching vibrations, also a decrease in N-H vibration is observed above $3000 \mathrm{~cm}^{-1}$. 
A mechanical analysis, comparing the DBHF-POXI modified membranes and the pristine POXI membrane, was carried out. For the pristine membrane, a Young modulus of $193 \pm 19 \mathrm{MPa}$ was obtained with stress and strain values at break of $7 \pm 1 \mathrm{MPa}$ and $7 \pm 2 \%$, respectively. For membranes crosslinked with DBHF, the values were $188 \pm 11 \mathrm{MPa}$ (Young Modulus), $6 \pm 1 \mathrm{MPa}$ (stress) and $5 \pm 1 \%$ (strain). The results show that, as consequence of the modification, the stress and strain limits are slightly reduced with the incorporation of crosslinked segments. The elastic modulus did not significantly change [42]. The results confirmed that the POXI good mechanical properties, in terms of elasticity and brittleness, are maintained after crosslinking, meaning that the membranes can be used for separation under pressure.

Contact angle measurements (Figure 6) show a decrease of hydrophobicity, when nonpolar modifiers were used. As the reaction takes place, the $\mathrm{N}-\mathrm{H}$ bonds on the surface are replaced by $\mathrm{N}-\mathrm{C}$ bonds, decreasing in this way the possibility of hydrogen bonds with water, and therefore the hydrophilicity [43]. However, when a polar modifier like DBD is used, the membrane becomes more hydrophilic, compared to the POXI pristine membrane. The hydrophilicity of the DBD-POXI modified membranes can be attributed to the polar carbonyl groups. In addition, nucleophilic attack on DBD could occur on the carbonyl group, generating a $-\mathrm{OH}$ group, which would contribute to the hydrophilicity [44-46].

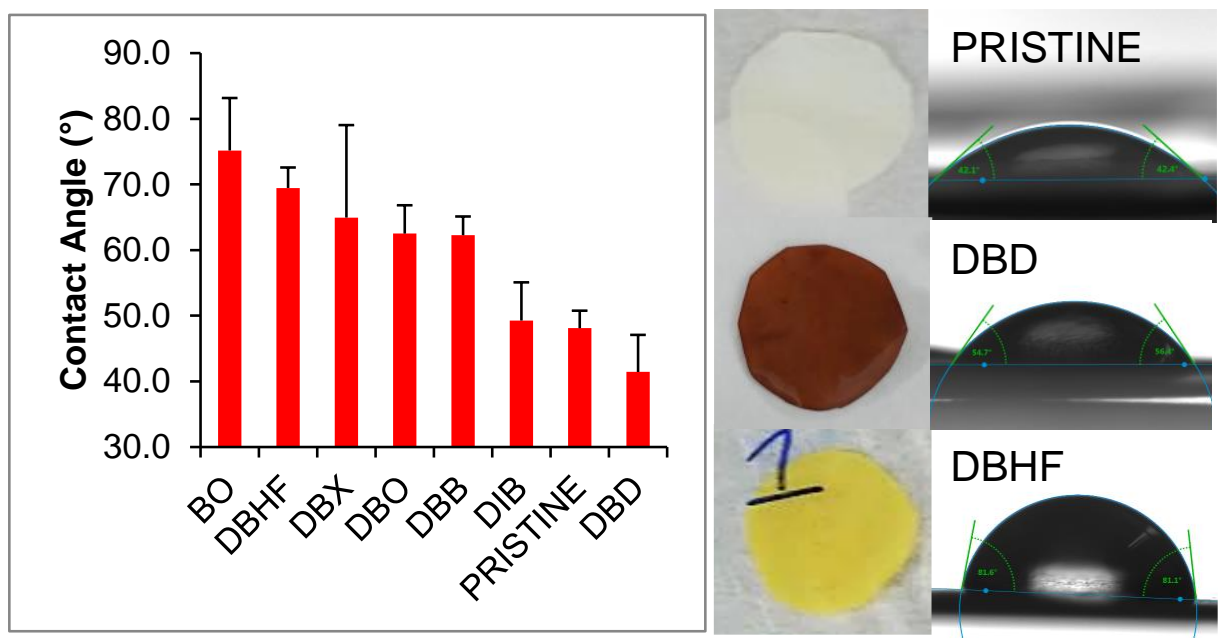

Figure 6. Water contact angle measurements for modified POXI membranes (left). POXI pristine (non-crosslinked) and DBD, DBHF modified membranes and respective image of water droplets on their surface (right).

\subsection{Organic solvent resistance}

POXI is intrinsically resistant to several organic solvents. The membranes can be used without further modification for filtration applications in alcohols, acetone, acetonitrile and hexane as well as in a wide range of $\mathrm{pH}(0-14)$ and oxidative environments as hot 
Fenton's reagent. However, the pristine (unmodified) polymer is soluble in polar aprotic solvents like DMF, DMAc, DMF and DMSO. The crosslinking strategy described above had the main purpose of enabling applications in these environments. Among all tested crosslinkers, DBHF provided the POXI membrane with the best resistance towards those organic solvents. The organic solvent resistance of the DBHF-POXI membranes was tested over 40 days; equal size membranes samples were immersed in one of the selected solvents. The DBHF modified membranes remained visually unaffected. A piece of unmodified POXI membrane was solubilized in NMP and this solution was used as a standard. The integrity of the membranes upon exposure to different solvents was expressed by Equation 1, after measuring changes in UV absorption $(277 \mathrm{~nm})$. The results are shown in Figure 7a. It can be seen that crosslinked membranes with DBHF are stable in all tested solvents, with around $98 \%$ resistance towards polar aprotic solvents.

Followed by these findings, the permeance values tested for DMSO, NMP, DMF and DMAc were evaluated at ambient temperature from a DBHF crosslinked membrane cast from a $14 \mathrm{wt} \%$ NMP POXI solution. The permeance values are lower than those obtained in water for membranes prepared in analogous conditions. However membranes in these organic solvents tend to swell, changing the pore size and therefore permeation properties. Figure $7 \mathrm{~b}$ shows how permeance correlates with the solvent viscosities. As viscosity increases, permeance decreases. DMF was chosen for high temperature tests due to better permeance values in comparison with other solvents and because it's a widely used solvent for potential membrane reactor applications. DBHF-POXI modified membranes were tested up to $120^{\circ} \mathrm{C}$ in DMF at 7 bar (Figure $7 \mathrm{c}$ and $7 \mathrm{~d}$ ). The rejections of Rhodamine B (480g/mol) and Red Direct $80(1375 \mathrm{~g} / \mathrm{mol})$ were respectively $78 \%$ and $99 \%$. The, rejection of Direct Red 80 was constant at least up to $70^{\circ} \mathrm{C}$. 


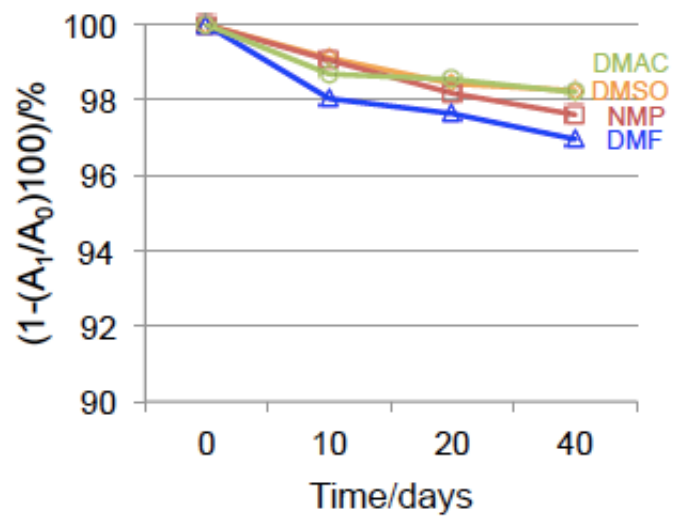

(a)

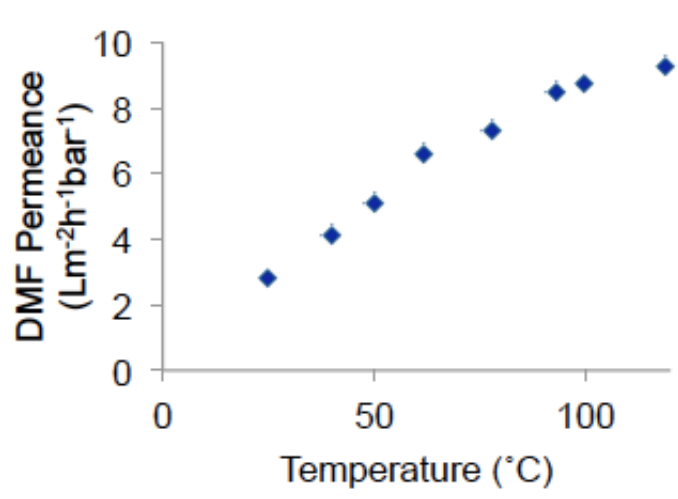

(c)

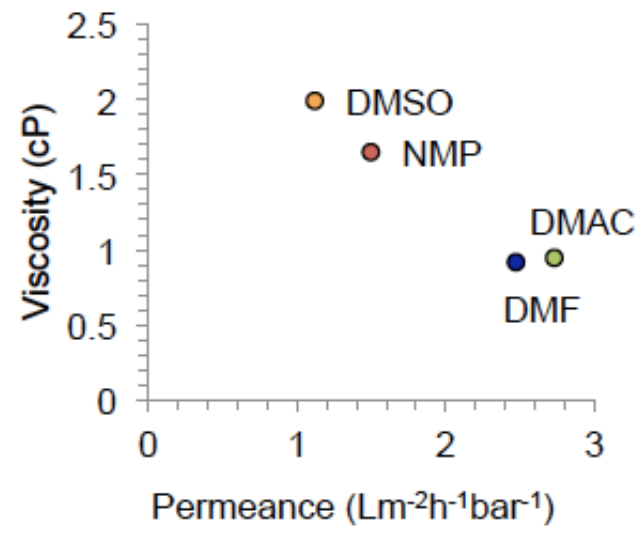

(b)

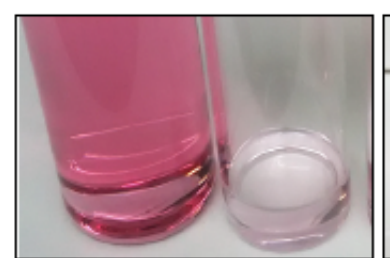

Red Direct 80 filtration in hot DMF $\left(70^{\circ} \mathrm{C}\right)$. Feed (left) and permeate (right).

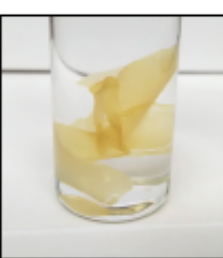

Membrane in pure DMF after filtration.

(d)

Figure 7. (a) Integrity of DBHF-modified POXI membranes (Equation 1) exposed to organic solvents during 40 days. Solvents: DMAc, DMSO, NMP and DMF; (b) Solvent viscosity as a function of their permeance in DBHF-POXI membranes; (c) Pure DMF permeance as a function of temperature; (d) Filtration of Red Direct 80 in DMF at $70^{\circ} \mathrm{C}$.

\section{Conclusions}

Herein we report, for the first time, the manufacture of porous asymmetric poly(oxindolebiphenylylene)-based membranes, using the non-solvent induced phase separation method. The polymer membranes display stability in temperatures as high as $500{ }^{\circ} \mathrm{C}$. Since the polymer under study is soluble in common organic solvents, the same manufacturing methods used for currently commercial membranes could be utilized. The membrane separation performance was investigated, placing their selectivity in the ultrafiltration range.

Additionally, by crosslinking the membranes with a series of bifunctional halides the membrane stability in organic solvents, such as DMSO, NMP, DMF and DMAc, was achieved. The efficiency of the crosslinker and the properties of the membranes were compared. The thermal stability of membranes crosslinked with dibromohexafluoropentane, was the highest one, with a degradation step starting at 
$329^{\circ} \mathrm{C}$. The crosslinked polymer membrane rejected $99 \%$ of Red Direct 80 in DMF at $70^{\circ} \mathrm{C}$. With these developments, high temperature and organic solvent stability, we can potentially extend the range of applications for polymeric membranes into conditions practically only currently covered by ceramic ones.

\section{Acknowledgement}

This work was sponsored by King Abdullah University of Science and Technology (KAUST).

\section{References}

[1] E. Drioli, P. Gianluca Di, Future Progress in Membrane Engineering, in: Handbook of Membrane Separations, CRC Press, 2015, pp. 825-846.

[2] S.P. Nunes, K. Peinemann, Membrane Technology: in the Chemical Industry, second ed., Wiley-VCH, Weinheim, Germany, 2006.

[3] V. Gitis, G. Rothenberg, Ceramic Membranes: New Opportunities and Practical Applications, Wiley-VCH, Weinheim, Germany, 2016.

[4] R. Weber, H. Chmiel, V. Mavrov, Characteristics and application of new ceramic nanofiltration membranes, Desalination, 157 (2003) 113-125.

[5] M.A. Acheampong, R.J.W. Meulepas, P.N.L. Lens, Removal of heavymetals and cyanide from gold mine wastewater, J. Chem. Technol. Biotechnol., 85 (2010) 590613.

[6] J. Borrini, G. Bernier, S. Pellet-Rostaing, A. Favre-Reguillon, M. Lemaire, Separation of lanthanides(III) by inorganic nanofiltration membranes using a water soluble complexing agent, J. Membr. Sci., 348 (2010) 41-46.

[7] G. Christian, S. Adam, Ceramic Membranes Technology: Current Applications and Future Development, in: Handbook of Membrane Separations, CRC Press, 2015, pp. 215-258.

[8] S. Luque, D. Gómez, J.R. Álvarez, Industrial Applications of Porous Ceramic Membranes (Pressure - Driven Processes), in: Membrane Science and Technology, Elsevier, 2008, pp. 177-216.

[9] M. Haubs, F. Herold, C. Krieg, U. Meyer - Blumenroth, J. Schneider, R. Wagener, J. Wildhardt, Membranes of high performance polymers, Makromolekulare Chemie. Macromolecular Symposia, 50 (1991) 67-78.

[10] J.R. Klaehn, C.J. Orme, E.S. Peterson, F.F. Stewart, J.M. Urban-Klaehn, High Temperature Gas Separations Using High Performance Polymers, in: Membrane Science and Technology, 2011, pp. 295-307.

[11] K. Treffry-Goatley, J. Gilron, The application of nanofiltration membranes to the treatment of industrial effluent and process streams, Filtr. Sep., 30 (1993) 63-66,54. [12] C. Ba, J. Langer, J. Economy, Chemical modification of P84 copolyimide membranes by polyethylenimine for nanofiltration, J. Membr. Sci., 327 (2009) 4958.

[13] Y. Dai, X. Jian, S. Zhang, M.D. Guiver, Thin film composite (TFC) membranes with improved thermal stability from sulfonated poly(phthalazinone ether sulfone ketone) (SPPESK), J. Membr. Sci., 207 (2002) 189-197. 
[14] K. Sarayu, S. Sandhya, Current technologies for biological treatment of textile wastewater-A review, Appl. Biochem. Biotechnol., 167 (2012) 645-661.

[15] L. Peeva, J. Arbour, A. Livingston, On the potential of organic solvent nanofiltration in continuous heck coupling reactions, Org. Process Res. Dev., 17 (2013) 967-975.

[16] L. Peeva, J. Da Silva Burgal, S. Vartak, A.G. Livingston, Experimental strategies for increasing the catalyst turnover number in a continuous Heck coupling reaction, J. Catal., 306 (2013) 190-201.

[17] J. Dreimann, P. Lutze, M. Zagajewski, A. Behr, A. Górak, A.J. Vorholt, Highly integrated reactor-separator systems for the recycling of homogeneous catalysts, Chem. Eng. Process.: Process Intensif., (2015).

[18] C. Linder, M. Perry, M. Nemas, R. Katraro, Solvent stable membranes, in, US Patent 5039421, 1991.

[19] P. Marchetti, M.F. Jimenez Solomon, G. Szekely, A.G. Livingston, Molecular separation with organic solvent nanofiltration: A critical review, Chem. Rev., 114 (2014) 10735-10806.

[20] P. Vandezande, L.E.M. Gevers, I.F.J. Vankelecom, Solvent resistant nanofiltration: Separating on a molecular level, Chem. Soc. Rev., 37 (2008) 365-405. [21] A.K. Hołda, I.F.J. Vankelecom, Understanding and guiding the phase inversion process for synthesis of solvent resistant nanofiltration membranes, J. Appl. Polym. Sci., 132 (2015).

[22] J. da Silva Burgal, L.G. Peeva, S. Kumbharkar, A. Livingston, Organic solvent resistant poly(ether-ether-ketone) nanofiltration membranes, J. Membr. Sci., 479 (2015) 105-116.

[23] D. Chen, S. Yu, H. Zhang, X. Li, Solvent resistant nanofiltration membrane based on polybenzimidazole, Sep. Purif. Technol., 142 (2015) 299-306.

[24] I.B. Valtcheva, P. Marchetti, A.G. Livingston, Cross linked polybenzimidazole membranes for organic solvent nanofiltration (OSN): Analysis of crosslinking reaction mechanism and effects of reaction parameters, J. Membr. Sci., 493 (2015) 568-579.

[25] S.P. Sun, T.S. Chung, K.J. Lu, S.Y. Chan, Enhancement of flux and solvent stability of Matrimid $囚$ thin-film composite membranes for organic solvent nanofiltration, AIChE J., 60 (2014) 3623-3633.

[26] D.Y. Xing, S.Y. Chan, T.S. Chung, The ionic liquid [EMIM]OAc as a solvent to fabricate stable polybenzimidazole membranes for organic solvent nanofiltration, Green Chem., 16 (2014) 1383-1392.

[27] H. Siddique, E. Rundquist, Y. Bhole, L.G. Peeva, A.G. Livingston, Mixed matrix membranes for organic solvent nanofiltration, J. Membr. Sci., 452 (2014) 354-366. [28] H. Maab, S. Pereira Nunes, Porous polyoxadiazole membranes for harsh environment, J. Membr. Sci., 445 (2013) 127-134.

[29] S. Chisca, P.H.H. Duong, A.H. Emwas, R. Sougrat, S.P. Nunes, Crosslinked copolyazoles with a zwitterionic structure for organic solvent resistant membranes, Polym. Chem., 6 (2015) 543-554.

[30] D. Gomes, S.P. Nunes, Fluorinated polyoxadiazole for high-temperature polymer electrolyte membrane fuel cells, J. Membr. Sci., 321 (2008) 114-122. 
[31] M. Boaventura, M.L. Ponce, L. Brandão, A. Mendes, S.P. Nunes, Proton conductive membranes based on doped sulfonated polytriazole, Int. J. Hydrogen Energy, 35 (2010) 12054-12064.

[32] D.R. Nieto, S. Fomine, M.G. Zolotukhin, L. Fomina, M. Del Carmen Gutiérrez Hernandez, Superelectrophilic activation of N-substituted isatins: Implications for polymer synthesis, a theoretical study, Macromol. Theory Simul., 18 (2009) 138144.

[33] M.C.G. Hernandez, M.G. Zolotukhin, S. Fomine, G. Cedillo, S.L. Morales, N. Fröhlich, E. Preis, U. Scherf, M. Salmón, M.I. Chávez, J. Cárdenas, A. Ruiz-Trevino, Novel, metal-free, superacid-catalyzed "click" reactions of isatins with linear, nonactivated, multiring aromatic hydrocarbons, Macromolecules, 43 (2010) 69686979.

[34] A.R. Cruz, M.C.G. Hernandez, M.T. Guzmán-Gutiérrez, M.G. Zolotukhin, S. Fomine, S.L. Morales, H. Kricheldorf, E.S. Wilks, J. Cárdenas, M. Salmón, Precision synthesis of narrow polydispersity, ultrahigh molecular weight linear aromatic polymers by A 2 + B 2 nonstoichiometric step-selective polymerization, Macromolecules, 45 (2012) 6774-6780.

[35] E. Martínez-Mercado, F.A. Ruiz-Treviño, A. Cruz-Rosado, M.G. Zolotukhin, A. González-Montiel, J. Cárdenas, R.L. Gaviño-Ramírez, Tuning gas permeability and selectivity properties by thermal modification of the side groups of poly(oxindolebiphenylylene)s membranes, Ind. Eng. Chem. Res., 53 (2014) 1575515762.

[36] Y. Lim, S. Lee, H. Jang, T. Hong, J. Yoo, J. Ha, D. Lee, W. Kim, Preparation and characterization of grafted propane sulfonic acid polyphenylene membrane via superacid-catalyzed reaction, Int. J. Hydrogen Energy, 39 (2014) 21613-21619. [37] S. Loeb, S. Sourirajan, Sea Water Demineralization by Means of an Osmotic Membrane, in: Saline Water Conversion-II, AMERICAN CHEMICAL SOCIETY, 1963, pp. 117-132.

[38] M. Ulbricht, Advanced functional polymer membranes, Polymer, 47 (2006) 2217-2262.

[39] L.I. Olvera, M.T. Guzmán-Gutiérrez, M.G. Zolotukhin, S. Fomine, J. Cárdenas, F.A. Ruiz-Trevino, D. Villers, T.A. Ezquerra, E. Prokhorov, Novel high molecular weight aromatic fluorinated polymers from one-pot, metal-free step polymerizations, Macromolecules, 46 (2013) 7245-7256.

[40] I.B. Valtcheva, S.C. Kumbharkar, J.F. Kim, Y. Bhole, A.G. Livingston, Beyond polyimide: Crosslinked polybenzimidazole membranes for organic solvent nanofiltration (OSN) in harsh environments, J. Membr. Sci., 457 (2014) 62-72. [41] S.W. Benson, III - Bond energies, J. Chem. Educ., 42 (1965) 502.

[42] E. Sgreccia, J.F. Chailan, M. Khadhraoui, M.L. Di Vona, P. Knauth, Mechanical properties of proton-conducting sulfonated aromatic polymer membranes: Stressstrain tests and dynamical analysis, J. Power Sources, 195 (2010) 7770-7775. [43] E. Eren, A. Sarihan, B. Eren, H. Gumus, F.O. Kocak, Preparation, characterization and performance enhancement of polysulfone ultrafiltration membrane using PBI as hydrophilic modifier, J. Membr. Sci., 475 (2015) 1-8. 
[44] G. Hurwitz, G.R. Guillen, E.M.V. Hoek, Probing polyamide membrane surface charge, zeta potential, wettability, and hydrophilicity with contact angle measurements, J. Membr. Sci., 349 (2010) 349-357.

[45] K.Y. Law, Definitions for hydrophilicity, hydrophobicity, and superhydrophobicity: Getting the basics right, J. Phys. Chem. Lett., 5 (2014) 686-688. [46] J. Liu, X. Lu, Z. Xin, C.L. Zhou, Surface properties and hydrogen bonds of monofunctional polybenzoxazines with different $\mathrm{N}$-substituents, Chin. J. Polym. Sci. (Engl. Ed.), 34 (2016) 919-932. 